\title{
Do tree plantations support forest conservation?
}

\author{
Lise Dal Secco' and Romain Pirard² \\ 1 Centre d'Etudes et de Recherches sur le Développement International (CERDI), 2 Center for International Forestry Research (CIFOR)
}

\section{Key messages}

- Tree plantations potentially support natural forest conservation. The main hypothesis for this effect is that tree plantations substitute natural forests for production, especially when plantations achieve high productivity.

- An exhaustive review of the published literature shows a diversity of analytical approaches with theoretical modeling, econometrics or descriptive statistics as main categories.

- This diversity reflects the complexity of translating a simple assumption into models because of the many factors at play. The analysis is all the more necessary as the positive substitution effect is straightforward, but potential negative (as well as other positive) impacts resulting from feedback/indirect effects, e.g. displacement of deforestation or replication of successful policies elsewhere, require more sophisticated methods to be understood.

- There is a convergence of findings of reduced degradation of natural forests with the expansion of tree plantations, but also potential increased deforestation due to lower market value of natural forests in the absence of logging (or displacement effects).

- A main limitation of studies pointing to the risk of forest conversion resulting from plantation expansion is the lack of consideration of policies and regulations that could prevent such deforestation, e.g. protected areas established where risks are high.

- These results are likely to apply partially to the case of fuelwood collection by local people - with less degradation but no identified outcome in terms of deforestation - yet much depends on household characteristics and the respective locations of plantations and forests.

- The limited number of studies challenges any general recommendation, yet a promising way forward may be the promotion of highly productive plantations in strategic places where agricultural rents are low, while taking action at the demand level to avoid a rebound effect whenever the price elasticity of demand for wood products is high.

- Continued production in natural forests, in a sustainable manner, might also help prevent deforestation, with wood products sold on niche markets and at a higher price owing to premiums (e.g. certification).

\section{Introduction}

In a context where tropical deforestation and forest degradation continue on a large scale, the search for solutions has not been very successful. A number of observers have assumed the expansion of tree plantations ${ }^{1}$ over the last decades, predicted to proceed at even higher rates in the future, might relieve pressure on tropical forests. While tree plantations differ from natural forests in many ways, such as the variety of ecosystem services they provide and their impacts on local livelihoods, the assumption of a positive benefit from expansion merits further examination. Indeed, it is also of interest for current debates on the implementation of the REDD+ mechanism as one potential policy to for reducing emissions.

This policy brief will thus try to answer the question: "Do tree plantations support forest conservation?" The argument departs

1 We use the term 'tree plantations' to refer to plantations for productive purposes and whatever their scale, from vertically-integrated industrial plantations to smallholders. from the assumption that plantations rather than forest logging could produce timber or other wood products and in turn divert degrading activities from production in natural forests to these artificial ecosystems. This would be even more reasonable to expect in plantations established on degraded areas that enjoy easier access than remote forests, and with productivity achievements much more attractive, in the order of $15-50 \mathrm{~m}^{3} / \mathrm{ha} / \mathrm{yr}$ compared to a few $\mathrm{m}^{3}$.

However, two remarks must be made at the outset: First, the argument is undermined when plantations are established through conversion of natural forests, which happens across the tropics. This observation is obvious as deforestation occurs on the site as a result; yet the eventual implications can also be debated if plantations' productivity is of a different magnitude, and the partial conversion leads to strict conservation without production in the remaining natural forest.

Second, 'forest conservation' might refer to either reduced degradation or reduced deforestation, and the impacts might be 
different and even opposite depending on which dimension is considered (as illustrated by the previous remark). This illustrates the ambiguity of the issue of impacts on 'conservation' in existing analyses. $^{2}$

We undertake the first-ever exhaustive review of published evidence to present the state of the debate and to assess answers to the question. Due to the relatively limited number of studies on this question - 25 highly relevant articles were found - we study in detail the approaches and methods used. This is all the more important as both the quality and rigor of methods are uneven. Therefore, we classify articles on the basis of their methods and proceed differently from a meta-analysis, i.e. we do not provide statistics on findings because we cannot assume the (relatively small) corpus is homogeneous. Our approach, which pays great attention to methods, enables us to draw lessons for more comprehensive studies to come on the issue.

Our categories of articles are discussion papers, theoretical modeling, econometrics and descriptive statistics. These various approaches provide different kinds of outputs. They emphasize different phenomena, hence their complementarity and the need to consider them all to draw lessons, and to have a good understanding of the interactions between tree plantations and natural forests.

Note that discussion papers do not engage in a scientific treatment of the issue. Consequently, we used them merely to provide theoretical background and present the main assumptions, in the following section.

\section{Theoretical background and main assumptions}

In this section, we summarize the theory behind the argument, which appears to be straightforward. It refers to the substitution effect of timber production between plantations and natural forests. This substitution can be on-site when rural dwellers move from one source of forest products to another in the same area, i.e. they can collect the products by themselves and for their own consumption. It can also be off-site when plantations are established in areas beyond the forest landscape and for industrial purposes. In this case, the problem becomes global with the substitution potentially materializing through international trade. Plantations established in South Africa might alleviate pressure on forests located in other countries of eastern or southern Africa, for instance.

The productivity of plantations justifies their establishment and is key to their impacts on conservation in a world of

2 We attract the attention of the reader to the similarities with the theory of land sparing whereby more productive agriculture would lead to fewer areas allocated to agricultural production - in our case, highly productive plantations would lead to fewer areas allocated to timber production and in turn less natural forest being logged. The opposite view, i.e. land sharing whereby production and conservation take place in the same sites and at the same time, also resonates with our study as it would translate into more (sustainable) production from natural forests. However, there are also substantial differences with potential perverse impacts related to deforestation as discussed in this piece, e.g. when natural forests are converted to agriculture as a result of plantation development elsewhere. increasingly limited natural resources, including land. Their production per hectare is often of an order of magnitude above that of natural forests. They require these high productivity levels to be economically profitable as the costs of production from land purchase, clearing, planting, maintenance and harvesting are significant. In a number of cases, though, the clearing of land with standing forests (even if degraded) provides a substantial source of income and helps offset the up-front costs of establishment; a well-managed plantation estate can lower costs as much as natural forest management for productive purposes can be very expensive in certain conditions.

A number of authors point to critical differences in terms of products from both ecosystems. While plantations can offer standardized timber products with homogeneous characteristics, natural forests are potentially a source of precious woods with a greater diversity resulting from much longer rotations. Consequently, markets for both are sometimes segmented, which may make them less conducive to substitution, even if new technologies tend to fill that gap over time.

Although this theory and its related assumptions are straightforward, their translation into models is much more complex. This critical step from intuition and logical reasoning to empirical evidence, or at least from intuition to proper modeling, explains the variety of approaches in the literature. Some focus on local extraction by villagers, while others look at national or international trade. By studying these models, we can identify specifics that make the story deeper and more complex than the basic argument suggests.

Models also need to account for displacement effects, as the land allocated to the plantation is no longer available for other land uses such as agriculture. These effects are real, but not always addressed by scientists, depending on the methods applied. The same remark holds for the feedback effects, e.g. in terms of prices and evolution of demand, which must be accounted for in a dynamic environment, but which are not always analyzed properly. As we will report later, the price effect through the evolution of demand might play an important role in the final outcome.

Further, in many countries, government policy and ownership of forests is highly influential in plantation establishment and forest designation. While this tends to be covered better at national levels, it also means that global modeling could tend to overplay the role of market influences and underplay political and social influences.

\section{Descriptive statistics: Plantations are taking over}

Descriptive statistics are a straightforward approach, reflecting on and organizing data to describe phenomena. They are descriptive in the sense that they barely explain indirect effects. These limitations make us use their results cautiously. In other words, the substitution effect that underpins the argument of positive impacts of plantations for conservation is only analyzed through figures that compare the potential or actual relative production for both sources. They have no spatial analysis that would support assumptions about real effects, e.g. by pointing to actual interactions in given locations (from local to national or even regional). In addition, they cannot account for general equilibrium effects, and put less emphasis on the effects of trade than other methods. 
Table 1. Distribution of the literature based on type of method and scale of application.

\begin{tabular}{|c|c|c|c|}
\hline Method Scale & Local & National & Global \\
\hline \multirow[t]{6}{*}{ Discussion } & & & Sargent (1992) \\
\hline & & & Victor and Ausubel (2000) \\
\hline & & & Cossalter and Pye-Smith (2003) \\
\hline & & & Binkley (2005) \\
\hline & & & Friedman (2008) \\
\hline & & & Paquette and Messier (2009) \\
\hline \multirow[t]{7}{*}{ Descriptive statistics } & & Clapp (2001) & Sedjo and Botkin (1997) \\
\hline & & Binkley et al. (2005) & Sedjo (1999) \\
\hline & & & Waggener (2001) \\
\hline & & & Sedjo (2001) \\
\hline & & & Bowyer (2005) \\
\hline & & & Ince (2010) \\
\hline & & & Warman (2014) \\
\hline \multirow[t]{4}{*}{ Theoretical models } & Koehlin and Parks (2001) & Hamilton (1997) & Von Amsberg (1994) \\
\hline & Linde-Rahr (2003) & & Sohngen et al. $(1997,1999)$ \\
\hline & Jumbe and Angelsen (2011) & & Sembres et al. (2011) \\
\hline & & & Heilmayr (2014) \\
\hline \multirow[t]{4}{*}{ Econometric models } & Koehlin and Parks (2001) & & Sembres et al. (2011) \\
\hline & Linde-Rahr (2003) & & Heilmayr (2014) \\
\hline & Jumbe and Angelsen (2011) & & \\
\hline & Ainembabazi and Angelsen (2014) & & \\
\hline
\end{tabular}

The increase in global wood production over time took place in parallel with a relative removal of natural forests from production and the increasing share of supply from plantations. Such a trend might support the assumption that substitution occurred, even though, once again, no analysis of the relationship is provided. Yet future scenarios are also produced to explore the case further. Warman (2014), for example, presents global trends in wood production over 1945-2030; predictions are either based on historical trends or on the design of various growth scenarios in plantation areas associated with a review of outlook studies. He concludes that wood production from natural forests declined after peaking in 1989, with tree plantations filling the gap. Predictions confirm this "pattern of declining wood production from natural forests." However, their relative share in future will depend on the capacity of investors to finance expansion of plantation estates and/or an increase in the productivity of existing estates, as well as the evolution of demand overall.

Productivity plays an important role, which is emphasized by these descriptive statistics. Because natural forests also provide a variety of goods or services in addition to provisioning services, they can barely compete with plantations usually focused on wood products for sustained yields per hectare. The contrast is striking given that industrial plantations meet about one-third of the total global industrial wood demand (Jürgensen et al. 2014), but represent only a fraction of all forested areas (between 50-120 million ha of productive plantations depending on the definitions and scope, out of 4 billion ha of forests worldwide).

\section{Theoretical modeling: The key roles of market interactions and land rents}

Most references in the literature present modeling efforts at local and global levels rather than at a national scale (Table 1). They are useful in their capacity to test a number of assumptions with empirical simulations, although this is neither a requirement nor systematic in the reviewed articles. Their interest is also largely in how they consider counterfactual scenarios as this approach leads to a comparison of a world with and without plantation expansion. This approach has more of a chance to clarify the factors behind the impacts on forest conservation; the models must spell out the reasons why impacts move in one or the other direction.

But the category of theoretical modeling is highly heterogeneous in many ways. On the one hand, it can focus on the local scale with a study of households' behavior with respect to fuelwood collection. On the other, it could examine the global scale with predictions of demand and supply from various sources and follow the logic of general equilibrium analysis. These broad sub-categories can be further distinguished by such factors as demand elasticity (how consumers react to lower prices), the capacity of a model to allow for direct land competition between agriculture and forestry, the existence of different forest classes with associated productivity or the recognition of spatial location of various sources. Despite these differences, models that operate at a global scale tend to emphasize price effects and provide insights that can be missed in descriptive statistics. 
One crucial benefit is the use of the Von Thünen framework (spatial economics) to reflect land rents and to study the impacts of shocks and policy changes. This model is deterministic as decisions are assumed to depend on the expected returns of land uses; changes in land rents induce changes in land use. The closer the land to cities and their markets, the more intensive the land use for higher value purposes. This results, for example, in agriculture and the production of perishable goods close to markets, low-intensity forestry far away and timber plantations in between. Applying the framework to this analysis helps demonstrate the key role of price elasticity of demand. Indeed, when markets exhibit a high demand elasticity, the prices for forest products will be more stable in a period of tree plantation expansion, and the changes in land use will be less important.

Studies subject to theoretical modeling are also interesting as the design of the model can determine the outcome. This observation is to be taken seriously, as it points to a critica phenomenon that might significantly shape the expected impacts of plantation expansion. Indeed, some models do not account for the competition in access to land, which produces one severe consequence: the establishment of plantations does not displace other land uses in forested areas where deforestation would then eventually take place. This is key to understanding the impacts of plantations, as in many cases (and in an increasing number of cases with less land available for development and associated scarcity of usable land), agricultural development will lead to the conversion of natural forests. This indirect effect is not always reflected by the models because of flawed or incomplete design. As a result, they show reduced degradation, but leave aside the other and less pretty side of the story, namely deforestation.

Household-level studies are devoted to fuelwood extraction as a source of forest degradation. The impacts are observed on site in that models look at decisions made by households among previously identified sources. No impact is expected to happen beyond this area and trade is not addressed. The models rely on the maximizing of utility by individuals to simulate choices of wood sources; this utility is calculated based on observable parameters, especially distance and associated requirements (time and overall cost of transportation).

\section{Econometric models: Emphasizing the role of the price elasticity of demand}

Econometric studies, the third category, are mostly used to test theoretical models presented in the previous section. These econometric studies are useful in their capacity to point out context and the extent of its influence on the impacts of plantations on forests. This might include, for example, land rents or the price elasticity of demand.

This elasticity, which is a critical element of the analysis, is usually determined through global trade analysis. Models show that positive impacts on the conservation of natural forests depend very much on a low elasticity that prevents demand from soaring when markets are supplied with new sources of wood. Otherwise, a rebound effect is expected because consumers tend to buy more when prices decline and goods become affordable.
These models also have the benefit of pointing out another interesting aspect of the story; degradation may eventually lead to deforestation. Numerous studies about the processes of deforestation across the tropics address this issue. One process with this impact is the construction of roads to manage forest concessions that boost investments in the area. It is good to have this impact acknowledged in this context. It means, in turn, that any effort to tackle degradation might also lead to avoided deforestation.

We stress this fact because the debate about plantations and forest conservation often overlooks it. But there is also the other side of the coin to consider: when natural forests are not logged for timber production (in a sustainable way), their economic value is lower; they might be threatened for this exact reason, as long as land ownership and government regulations enable changes in land use. Indeed they become more prone to conversion as they are less competitive against agricultural rents. In this respect, a lot seems to depend on whether agricultural rents are high (high risk, negative impacts) or low (low risk, overall positive impacts more likely).

At the household level, various econometric methods are applied, ranging from binary or multinomial qualitative models to impact evaluation with difference-in-difference. Overall, a lot seems to depend on household characteristics such as level of education of the head, livestock endowment, size or distance to the various sources of fuelwood. Characteristics of plantations such as size and location are also relevant.

\section{Reduced degradation is expected, but deforestation is looming}

Based on the broad range of published studies, we were able to cover insights generated through a variety of methodological approaches. This is important, as depending on the methods, results may differ and point to complementary or even contradictory impacts on forest conservation. Using categories of studies associated with methodological approaches was also a key condition to identify more, or less, rigorous and reliable studies from a scientific point of view.

About half of the articles in our corpus are either of a discussion (no specific evidence produced) or descriptive statistics (no modeling of interactions or thorough analysis of the factors of change). This means they can hardly be considered as providing new and solid evidence of the impacts of the expansion of timber plantations on forest conservation. Their ability to explain the mechanics of these impacts in a satisfactory way can be questioned, and they might be prone to subjectivity in a number of cases. For instance, it might be misleading to consider one fixed demand and one given rate of expansion of tree plantations, and then deduce the area of natural forests that can be spared from degradation and/or conversion. Nevertheless, these studies are useful in their own ways as they frame the debate and provide orders of magnitude with trends. They also provide interesting information in terms of productivity, spatial location of the expansion and historical trends. 
Table 2. Main results for each article of the sample (except for discussion-type articles).

\begin{tabular}{|c|c|}
\hline Reference & Main Result \\
\hline \multicolumn{2}{|l|}{ Local } \\
\hline Ainembabazi and Angelsen (2014) & $\begin{array}{l}\text { The introduction of commercial timber plantations has reduced the natural forest } \\
\text { production by } 15.5 \% \text { compared to the counterfactual situation. }\end{array}$ \\
\hline Jumbe and Angelsen (2011) & $\begin{array}{l}\text { A one hectare increase in plantation area reduces fuelwood collection in customary forests } \\
\text { by } 2 \% \text {. }\end{array}$ \\
\hline Linde-Rahr (2003) & $\begin{array}{l}\text { Wood from plantations and from natural forests are substitutes: a 1-unit decrease in the } \\
\text { shadow wood price from plantations decreases the share of collection from open access } \\
\text { forests by } 0.3 \text { units. }\end{array}$ \\
\hline Koehlin and Parks (2001) & $\begin{array}{l}\text { Village woodlots reduce wood extraction from natural forests by } 13 \% \text {. Plantations should } \\
\text { not be established too close or too far away from natural forests. }\end{array}$ \\
\hline \multicolumn{2}{|l|}{ National } \\
\hline Binkley et al. (2005) & $\begin{array}{l}\text { United States Plantations will be able to respond to the entire increase in timber demand. } \\
\text { Demand pressure on natural forest will be halved. }\end{array}$ \\
\hline Clapp (2001) & $\begin{array}{l}\text { Chile Plantations captured traditional markets supplied by natural forests but this did not } \\
\text { reduce logging in natural forests because of a new external demand. }\end{array}$ \\
\hline Hamilton (1997) & $\begin{array}{l}\text { Indonesia Moderate demand increase and high dependence on timber plantations for } \\
\text { wood supply will reduce deforestation. }\end{array}$ \\
\hline \multicolumn{2}{|l|}{ Global } \\
\hline Heilmayr (2014) & $\begin{array}{l}\text { Plantations lead to lower areas of logged natural forests, yet this positive impact is } \\
\text { mitigated when the elasticity of demand is high. }\end{array}$ \\
\hline Warman (2014) & Wood supply from natural forests has peaked and supply from planted forests is growing. \\
\hline Sembres et al. (2011) & $\begin{array}{l}\text { Plantations increase the deforestation rate in countries with high agricultural rents. They } \\
\text { reduce this rate in countries with low agricultural rents. }\end{array}$ \\
\hline Ince (2010) & Emerging role of plantations in timber production. \\
\hline Bowyer et al. (2005) & Emerging role of plantations in timber production. \\
\hline Sedjo (2001) & $\begin{array}{l}\text { An innovation shock implies an increase in plantations' establishment that relieves pressure } \\
\text { on natural forests. }\end{array}$ \\
\hline Waggener (2001) & $\begin{array}{l}\text { Removal of natural forests from production and emerging role of timber production from } \\
\text { plantations. }\end{array}$ \\
\hline Sedjo (1999) & Increase in global wood production over time comes mostly from plantations. \\
\hline Sohngen et al. $(1997,1999)$ & $\begin{array}{l}\text { More plantations reduce long-term price levels by } 12 \% \text { and thus reduce harvest in remote } \\
\text { old-growth forests by } 15 \% \text { compared to the baseline scenario. }\end{array}$ \\
\hline Sedjo and Botkin (1997) & $\begin{array}{l}\text { Placing only } 5 \% \text { of the current forest area under intensive plantations would be enough to } \\
\text { meet the demand for wood products. }\end{array}$ \\
\hline von Amsberg (1994) & $\begin{array}{l}\text { With an inelastic demand, the increase in timber supply induced by plantations creates a } \\
\text { real drop in timber prices that leads to less degradation of natural forests. }\end{array}$ \\
\hline
\end{tabular}

Recent studies prove theoretical models are powerful tools to study household strategies and behavior for fuelwood collection. They show that household characteristics play a significant role in predicting the outcomes of the establishment of tree plantations devoted to energy production in rural areas. The respective locations of the forest and plantation are also critical factors that determine their relative access and associated transportation costs, which in turn lead to forest conservation or business-asusual forest degradation. But their limited scope to fuelwood extraction necessarily limits their lessons to a specific case (yet very substantial in the context of some developing countries).
Regarding econometric models (commonly used to test empirically the previous theoretical models), their insights refer to several key determinants of the impacts: the price elasticity of demand, the level of agricultural rents, and household preferences. While theoretical models already address household preferences, the other two determinants are more specific and extremely important for understanding and predicting the impacts of tree plantation expansion. Indeed, if the demand for wood products is very sensitive to price fluctuations on the markets, then a rebound effect can be expected that could partially or fully offset the positive impacts. This is to be taken seriously, as this rebound effect has been observed for other products historically, such as charcoal or various agricultural commodities. 
The issue of agricultural rents can be understood as follows: when wood products originate from additional tree plantations, the production potential of natural forests might be untapped as demand becomes satisfied. While this sounds like good news, a perverse effect can also materialize if agricultural rents are high enough in forested areas, as standing natural forests lose part if not all of their market value (not accounting for the range of non-market environmental services they still provide locally and globally). This, in turn, can lead to their conversion to other land uses as long as regulations do not prevent it.

This phenomenon illustrated an important finding of our review with a convergence among studies. The impacts on forest conservation have to be divided into more or less degradation, and more or less deforestation. Most studies and the terms of the debate lack clarity on this distinction, and many remain ambiguous with respect to the nature of the impacts on forest 'conservation' that they analyze. In the end, natural forests might be better off as a sustainable source of timber products to maintain their market value and provide a range of environmental services rather than being substituted by tree plantations for timber production and then converted into other land uses for their lack of economic attractiveness. Of course, in principle, the legal and ownership framework could prevent such changes. However, regulations more than often follow economic stimuli, and laws are poorly enforced because of economic prospects.

This implies that public support policies are required to secure positive impacts for forest conservation through the avoidance or mitigation of the rebound effect. They can do this by acting also on demand; promoting only highly productive plantations and efforts in increased productivity in existing estates; and paying special attention to places where high agricultural rents pose a high risk of further conversion with appropriate regulations and law enforcement.

\section{How to improve science: The way forward}

The findings from this review can be improved with further research. This should take stock of several methodological weaknesses and problems related to the availability and quality of data used and required by a variety of methodological approaches.

We noticed that econometric models in this domain face some critical limits because of the unavoidable endogeneity bias (caused by potential reversed causality). Here, we think in particular about the theory of the forest transition and especially the 'forest scarcity path.' According to this theory, tree plantations develop when natural forests are too scarce to fill the demand gap and as a reaction to the resulting increased market value of timber products. Then it might be first and foremost the scarcity of forests that shield against their degradation or conversion, rather than the resulting expansion of tree plantations. Besides this, econometric models should account for time lags between the establishment of plantations (with land clearing and planting operations) and their harvest six to several dozens of years later depending on the sites, species, quality and nature of products.

We also noticed the relative neglect of several important factors, such as market segmentation, public support policies and leakage/displacement effects. These should be better, and systematically, integrated into the models to strengthen results. Indeed, natural forests host precious and unique species that plantations can hardly compete with, and with rotations that are also rarely found in plantations for economic reasons. Consequently, the development of plantations may never be able to entirely spare natural forests from degradation, or at least from logging. Niche markets will continue that plantations will probably never replace, but their relatively small scale compared to commodities such as pulpwood or biomass energy should allow for sustainable production with limited degradation. With the intensification of international trade and better connectivity between places of production, processing and consumption, leakage and displacement effects also deserve more consideration in all studies in this field, even if some global studies already address them.

Modeling in its various forms, and the primacy of economic aspects and dynamics in many approaches, entail some limitations that relate to policies. In a world where forests are mostly owned by states, the negative indirect effects from the displacement of activities (mostly agriculture) depend on regulations and land tenure. Higher land prices and declining economic value of unlogged natural forests, for example, can lead to forest conversion. Of course, if these forests are protected by the state, or if their private owners have objectives and motivations that go beyond mere economic returns, these indirect effects might not, in theory, materialize. Regulations are not carved in stone, however, and many countries with tropical forests have weak law enforcement. There is thus room for these indirect negative effects to materialize in part. Having said that, these models and approaches would gain from being complemented by other disciplines of political science, governance and public administration, geography and even sociology to better reflect the complexity of the context and implications.

Data issues were also identified, especially with respect to running models on a global scale. We have reason to hope, however. The quality of these data is likely to improve a great deal owing to new research initiatives and monitoring, such as Global Forest Watch.

\section{References}

Ainembabazi JH and Angelsen A. 2014. Do commercial forest plantations reduce pressure on natural forests? Evidence from forest policy reforms in Uganda. Forest Policy and Economics 40:48-56. doi:10.1016/j.forpol.2013.12.003

Binkley CS. 2005. The environmental benefits of tree plantations. Journal of Sustainable Forestry 21(4): 5-14.

Binkley CS, Aronow ME, Washburn CL and New D. 2005. Global perspectives on intensively managed plantations: Implications for the Pacific Northwest. Journal of Forestry 103:61-64.

Bowyer JL, Howe DJ, Guillery P and Fernholz K. 2005. Fast-growth Tree Plantations for Wood Production: Environmental Threat Or a Means of 'Saving' Natural Forests. White Bear Lake, Dovetail Partners, Incorporated.

Clapp RA, 2001. Tree farming and forest conservation in Chile: Do replacement forests leave any originals behind? Society \& Natural Resources 14:341-356. doi:10.1080/08941920119176 
Cossalter C and Pye-Smith C. 2003. Fast-wood forestry: Myths and realities. Forest Perspectives 1. Bogor, Indonesia: Center for International Forestry Research.

Friedman ST. 2008. Environmental aspects of the intensive plantation/reserve debate. Journal of Sustainable Forestry 21:5973. doi:10.1300/J091v21n04_05

Hamilton C. 1997. The sustainability of logging in Indonesia's tropical forests: A dynamic input-output analysis. Ecological Economics 2:183-195.

Heilmayr R. 2014. Conservation through intensification? The effects of plantations on natural forests. Ecological Economics 105:204-210. doi:10.1016/j.ecolecon.2014.06.008

Ince PJ. 2010. Global sustainable timber supply and demand. In Sustainable Development in the Forest Products Industry. Porto, Portugal: Universidade Fernando Pessoa. 29-41.

Jumbe CBL and Angelsen A. 2011. Modeling choice of fuelwood source among rural households in Malawi: A multinomial probit analysis. Energy Economics 33:732-738. doi:10.1016/j. eneco.2010.12.011

Jürgensen C, Kollert W and Lebedys A. 2014. Assessment of industrial roundwood production from planted forests, Working Paper FP/48/E, FAO Planted Forests and Trees Working Paper Series, Food and Agriculture Organization of the United Nations, Rome.Köhlin G and Parks PJ. 2001. Spatial variability and disincentives to harvest: Deforestation and fuelwood collection in South Asia. Land Economics 77:206-218.

Linde-Rahr M. 2003. Property rights and deforestation: The choice of fuelwood source in rural Viet Nam. Land Economics 79:217. doi:10.2307/3146868

Paquette A and Messier C. 2009. The role of plantations in managing the world's forests in the Anthropocene. Frontiers in Ecology and the Environment 8:27-34. doi:10.1890/080116

Sargent C. 1992. Natural Forest or Plantation? Plantation Politics: Forest Plantations in Development. London: Earthscan Publishers.
Sedjo RA. 2001. The economic contribution of biotechnology and forest plantations in global wood supply and forest conservation. Presentation, College of Forestry. Stevenson, Washington: Oregon State University, 21-27 July 2001.

Sedjo RA. 1999. The potential of high-yield plantation forestry for meeting timber needs. In Boyle JR, Winjum JK, Kavanagh K and Jensen EC, eds. Planted Forests: Contributions to the Quest for Sustainable Societies. Oregon State University: Springer. 339-359.

Sedjo RA and Botkin D. 1997. Using forest plantations to spare natural forests. Environment: Science and Policy for Sustainable Development 39:14-30. doi:10.1080/00139159709604776

Sembres T, Kontoleon A and Brown C. 2009. Understanding the impact of timber plantations on tropical deforestation: A cross country analysis. Working Paper. http://bioecon-network.org/ pages/11th_2009/Sembres.pdf

Sohngen B, Mendelsohn R and Sedjo R. 1999. Forest management, conservation and global timber markets. American Journal of Agricultural Economics 81:1-13. doi:10.2307/1244446

Sohngen B, Mendelsohn R, Sedjo R and Lyon K. 1997. An Analysis of Global Timber Markets. Washington, DC: Resources for the Future.

Victor DG and Ausubel JH. 2000. Restoring the forests. Foreign Affairs 79(6):127-144.

Von Amsberg J. 1994. Economic parameters of deforestation. World Bank Economic Review 12:133-153.

Waggener T. 2001. Role of plantations as substitutes for natural forests in wood supply: Lessons learned from the Asia-Pacific region. Working Paper FP/7. Rome: Food and Agriculture Organization.

Warman RD. 2014. Global wood production from natural forests has peaked. Biodiversity and Conservation 23:1063-1078. doi:10.1007/s10531-014-0633-6 

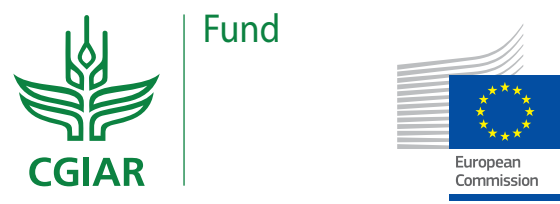